podnieść zastrzeżenia, co do objaśniania pewnych zjawisk. Czuję na przykład pewien niedosyt po lekturze tych partii książki, które dotyczyć mają genezy koncepcji loca sancta - tłumaczenie tego zagadnienia jest w mojej opinii nieco „mętne"; z kolei geneza kultu męczenników i relikwii w ogóle według mnie nie została uchwycona - przedstawione zostały pewne elementy, które się na ten kult składają i stanowią jego istotne wyróżniki, jednak przyczyny, które doprowadziły do jego powstania nie zostały w ogóle sprecyzowane, dyskusyjne bywa także dzielenie i nazywanie poszczególnych części pracy - trudno mi zgodzić się m.in. na nazwy podrozdziałów rozdziału III: 1 - „Przyczyny polityczne”, 2 „Przyczyny ideologiczno-kultowe”. Wobec tego, o czym jest w nich mowa należałoby raczej mówić o „przyczynach polityczno-ideologicznych” i „kultowych".

Chociaż wskazane powyżej błędy i potknięcia domagają się korekty, naniesienie niezbędnych poprawek pozostanie dla treści książki zabiegiem czysto „kosmetycznym”. Wspomniane niedociągnięcia nie wpływają bowiem w żaden sposób na wartość merytoryczną pracy. W postaci rozprawy doktor Pawłowskiej otrzymaliśmy do rąk niezwykle ważne studium, które w znacznym stopniu uzupełnia lukę, jaka istniała do tej pory nie tylko w nauce polskiej, lecz również światowej. Jest to z pewnością lektura godna polecenia dla każdego, kto się interesuje starożytnością chrześcijańską.

Jeżeli wolno mi na koniec wyrazić pewne życzenie, pragnąłbym, by Autorka Urbs Sacra wykorzystała w najbliższej przyszłości swoją olbrzymią wiedzę i pokusiła się o napisanie studium poświęconego pielgrzymowaniu, skupionego jednak tym razem na aspektach socjologicznych i antropologicznych. Ze względu na stan oraz charakter zachowanych źródeł z pewnością nie będzie to zadanie łatwe, o czym Autorka sama wie najlepiej. Jest ona jednak do tego jak najbardziej powołana, a sądząc po omawianej w tej recenzji książce efekt takiego przedsięwzięcia może zakończyć się wielkim sukcesem.

Juliusz Rogowski - Poznań, UAM

\begin{abstract}
Fabio RUGGIERO, La follia dei cristiani. La reazione pagana al cristianesimo nei secoli I-V. Prefazione di M. Simonetti, Roma 2002, Città Nuova Editrice, pp. 260.
\end{abstract}

L'Autore del libro, Fabio Ruggiero (nato nel 1959), è uno studioso di fama mondiale delle antichità cristiane ed è autore di numerose e preziose pubblicazioni patristiche, tra le quali anche alcune note ed apprezzate edizioni critiche.

Non appena il paganesimo antico si accorse dell'esistenza del cristianesimo nascente, una delle prime valutazioni date a questa nuova religione fu quella di 
follia (amentia, dementia, insania). Diverse e variegate erano le ragioni che causavano questo giudizio negativo. Una di esse consisteva nei comportamenti che i cristiani imponevano ai neofiti: il perdono, il sacrificio atto solo alla conquista della vita eterna. Anche la fede in Gesù, un uomo crocifisso e poi risorto, faceva parte del concetto di follia. Anche il semplice fatto che il Messia, ritenuto dai cristiani come divino ed universale, fosse nato in una insignificante e remota provincia dellImpero Romano costituiva motivo di diffidenza verso questo nuovo culto. Proprio di questa primissima reazione pagana nei confronti del cristianesimo nei secoli I-V tratta il libro del Prof. Ruggiero.

Il libro si apre con un „Prologo” (pp. 5-14) stilato dal famoso patrologo Manlio Simonetti, professore di Letteratura Cristiana Antica all'Università „La Sapienza” di Roma e all'Istituto Patristico „Augustinianum” di Roma. Segue una „Introduzione” (pp. 15-18), nella quale il Prof. Ruggiero, tra l'altro, rivela l'intento del suo libro: ,è la trattazione di una peculiare questione del dibattito tra la cultura antica e il cristianesimo: l'accusa fatta dai pagani e riguardante i cristiani che essi sono individui irrazionali, seguaci di un culto stupido, irrazionale, o addirittura folle" (p. 15). L'intento viene raggiunto dall'Autore attraverso l'analisi di una serie di testi e di pensatori, scelti tra i più significativi ed importanti che si incontrano nei primi cinque secoli dell'era cristiana (cf. p. 15). Nel libro vengono prevalentemente presi in esame documenti e fonti pagani. I testi cristiani forniti, invece, sono atti esclusivamente ad illustrare il senso e il significato del pensiero pagano in proposito.

Il capitolo I è intitolato: „Paolo di Tarso. La vita di Cristo tra lo scandalo e l'assurdo" (pp. 19-44). Per illustrare le reciproche relazioni tra l'Apostolo delle Genti e gli stessi gentili, il prof. Ruggiero fornisce ed analizza le seguenti fonti cristiane ed pagane: 1 Cor 1, 10 - 2, 5; 1Cor 3, 18-23; At 18, 1-2. 12-17; Orosio, Historia adversum paganos VII 6, 15; At 2,1-41; At 3, 1-4, 23; At 5, 14-42; At 16, 9-10; At 17, 16-34; At 18, 4-11; At 21, 17 - 23, 10; At 25, 13-24; At 26, 24-25; 1Cor 10, 14-17; Ignazio di Antiochia, Epistula ad Trallianos 9, 1-2; id, Epistula ad Romanos 6, 3; Giustino, Dialogus cum Tryphone 32, 1; id., Prima Apologia I 13, 4; Apuleio di Madaura, De deo Socratis 12.

Il capitolo II è dedicato al seguente tema: „Plinio il Giovane. Un giurisprudente scruta la comunità cristiana" (pp. 45-53) e, come si può supporre, analizza la famosa Epistula ad Traianum Imperatorem (X 96) del decimo libro delle lettere di Plinio il Giovane che governò la Bitinia come legatus pro praetore dal settembre del 111 alla sua morte, avvenuta intorno all'anno 113. Proprio in quel tempo Plinio conobbe una comunità cristiana e chiese lumi all'imperatore circa il modo con il quale comportarsi verso questa nuova, numerosa e vitale setta. La risposta, il famoso rescriptum Traiani (X 97), ai quesiti di Plinio è sobria e breve. Traiano contata che non esiste una procedura giuridica in proposito. I cristiani non devono essere ricercati, se però vengono accusati e ritenuti colpevoli di appartenere a questa loro religione, la loro 
ostinazione nel non ubbidire alle leggi e alle tradizioni dei Romani è sufficiente a farli condannare e punire.

Il capitolo III - „Apuleio di Madaura. La fede immorale della moglie del mugnaio" (pp. 54- 57) - presenta ed analizza il testo anticristiano di Apuleio, un intellettuale africano latino, uno dei più grandi ed originali scrittori latini dei tempi di Antonio; il testo è preso dalle Metamorfosi (IX 14).

„Gaio Svetonio Tranquillo. La superstizione straniera” è il titolo del capitolo IV (pp. 58-64). Qui l'Autore presenta la visione negativa del cristianesimo da parte di Svetonio. In particolare, viene analizzato dettagliatamente il testo della Vita dei Cesari. Nerone 16 e La Vita dei Cesari. Augusto 93.

I capitoli V e VI - „Epitteto. Falsa virtù ed ethos senza ragione” [pp. 65-75] e „Marco Aurelio. La continenza del filosofo e la teatralità del martire” [pp. 7693] - si occupano dei due importanti filosofi pagani: Epitteto di Ierapoli (Frigia), di Marco Aurelio, e specialmente delle loro opinioni circa il martirio cristiano.

Il capitolo VII riguarda Luciano di Samosata - „Luciano di Samosata. Ciarlatano e le sue ingenue vittime" (pp. 94-102) - e analizza prevalentemente il De morte Peregrini 11-13 e 16 di Luciano.

Il capitolo che segue presenta il filosofo e medico: „Galeno di Pergamo. La scuola di Cristo - la scienza senza il metodo" (pp. 103-116) il quale, come possiamo già intuire dal titolo del capitolo, critica la rozzezza e l'imprecisione scientifica della „Scuola di Cristo”. I testi di Galeno, che vengono interpretati, sono stati presi da: R. Walzer, Galen on Jews and Christians (London 1949, pp. 15-16).

Il capitolo IX: „Celso. La verità del paganesimo e la falsità della dottrina cristiana" (pp. 117-126) presenta con maestria i famosi frammenti dellAlethès lógos di Celso che si sono conservati nel Contra Celsum di Origene.

Il capitolo X è intitolato: „Porfirio di Tiro. L'irrazionalità dei cristiani nel periodo della crisi” (pp. 127-141). Il prof. Ruggiero ricostruisce in modo molto chiaro il pensiero di Porfirio circa il cristianesimo soltanto dai frammenti rimasti dopo l'ordine, dato nel 448 dagli imperatori cristiani Teodosio II e Valentiniano III, di bruciare tutte le opere del filosofo pagano (cf. Codex Iustinianus I 1, 3), nonché da allusioni, più o meno esplicite, disseminate in autori paleocristiani cristiani. Questi frammenti ed allusioni sono stati raccolti e pubblicati da Adolf von Harnack nel 1916.

Con il capitolo X è collegato il capitolo XI: „L'avversario di Macario di Magnesia. Una critica degli scritti cristiani” (pp. 142-157). Il Prof. Ruggiero, infatti, analizza qui dei brani tratti dallopera di Macario (Apocriticus), che è un dialogo fittizio tra un cristiano e un pagano. Nella critica del cristianesimo, mossa dal pagano, ritroviamo i temi del Contra christianos di Porfirio di Tiro.

Il capitolo XII analizza la posizione e il comportamento verso i cristiani degli imperatori pagani Galerio e Massimino Daia sul titolo „Galerio e Massi- 
mino Daia. Tra la tolleranza e le persecuzioni" (pp. 158-167), e il capitolo che segue è, anchesso, dedicato ad un imperatore pagano: Giuliano l'Apostata, l'ultimo imperatore pagano che cercò invano di ripristinare il paganesimo. Il capitolo è intitolato: „Giuliano l'A postata. Il cristianesimo - la malattia dell'anima" (pp. 168-183).

In ultimo, il XIV capitolo - „Ausonio e Rutilio. Due aristocratici di fronte al monachesimo", (pp. 184-197) - presenta il pensiero dei poeti pagani del IVV secolo: Ausonio e Rutilio Namaziano e, specialmente, la loro aspra critica del monachesimo cristiano nascente.

Il libro termina con un „Elenco delle abbreviazioni” (pp. 198-200), con un'ampia e preziosa bibliografia (pp. 201-243), e con l',Indice delle persone” (pp. 245-248).

Dall'ampio spettro dei testi e delle tematiche selezionate, si evince facilmente l'alto valore scientifico, storico e patristico del volume; già lodato da numerose recensioni, e pubblicato dalla più prestigiosa Editrice Città Nuova, conferma l'interesse per la problematica e offre una documentazione di grande profitto a un vasto pubblico, non solo specialistico ma anche impegnato a vario titolo nella ricerca della diffusione del paleocristianesimo e del suo ruolo geopolitico fin dall'antichità. La scorrevolezza dello stile e la maneggevolezza dell'edizione arricchiscono ulteriormente la fruibilità del libro.

Bazyli Degórski, O.S.P.P.E. - Roma, Angelicum

\section{Fabio RUGGIERO, Szaleństwo chrześcijan. Poganie wobec chrześcijaństwa w pierwszych pięciu wiekach, thum. E. Kukaszczyk, Wydawnictwo Apostolstwa Modlitwy, Kraków 2007, ss. 250.}

Choć książka Fabio Ruggiero została wydana w języku włoskim dosyć dawno (La follia dei cristiani. La reazione pagana al cristianesimo nei secoli I-V, Roma 2002, Città Nuova Editrice), to jednak ze względu na swoją treść i dzięki jej przekładowi na język polski oraz wydaniu przez Wydawnictwo WAM w 2007 r., zasługuje na uwagę nie tylko ze strony badaczy starożytności chrześcijańskiej. Autor zajmuje się bowiem tematem bardzo rzadko poruszanym przez uczonych zajmujących się chrześcijańską literaturą antyczną, a mianowicie postawą pogan wobec chrześcijaństwa. Temat ten jest systematycznie omijany przez badaczy historii pierwszych wieków chrześcijaństwa również z tego powodu, że bardzo utrudniony jest dostęp do tekstów pogańskich krytykujących chrześcijaństwo, gdyż w okresie pokonstantyńskim, często wręcz z nakazu cesarza, jak w przypadku Teodozjusza, były one systematycznie niszczone przez samych chrześcijan jako bluźniercze. Praca Ruggiero wpisuje się w nurt badań nad pogańską literaturą antychrześcijańską takich 